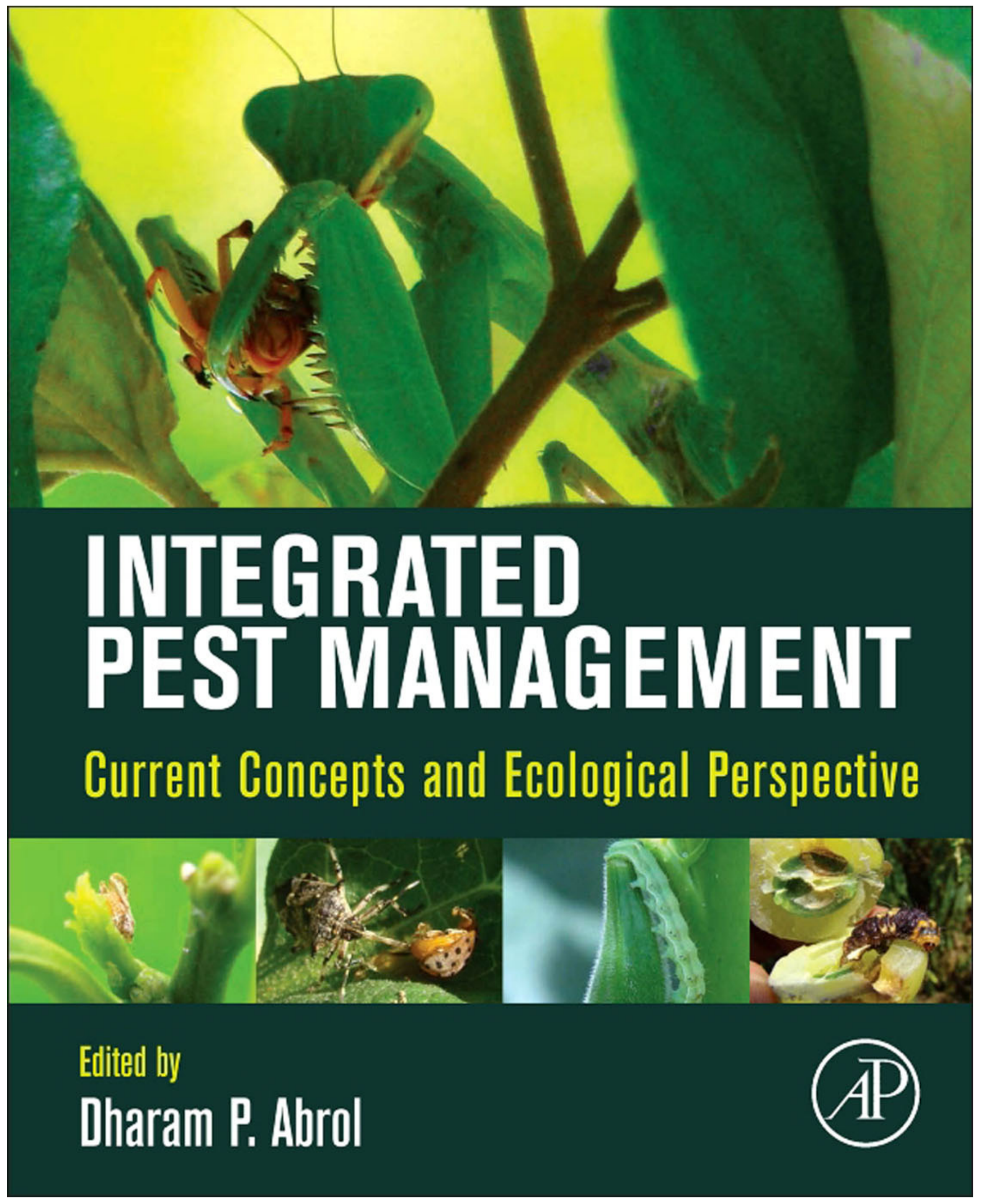




\section{INTEGRATED PEST MANAGEMENT}


This page intentionally left blank 

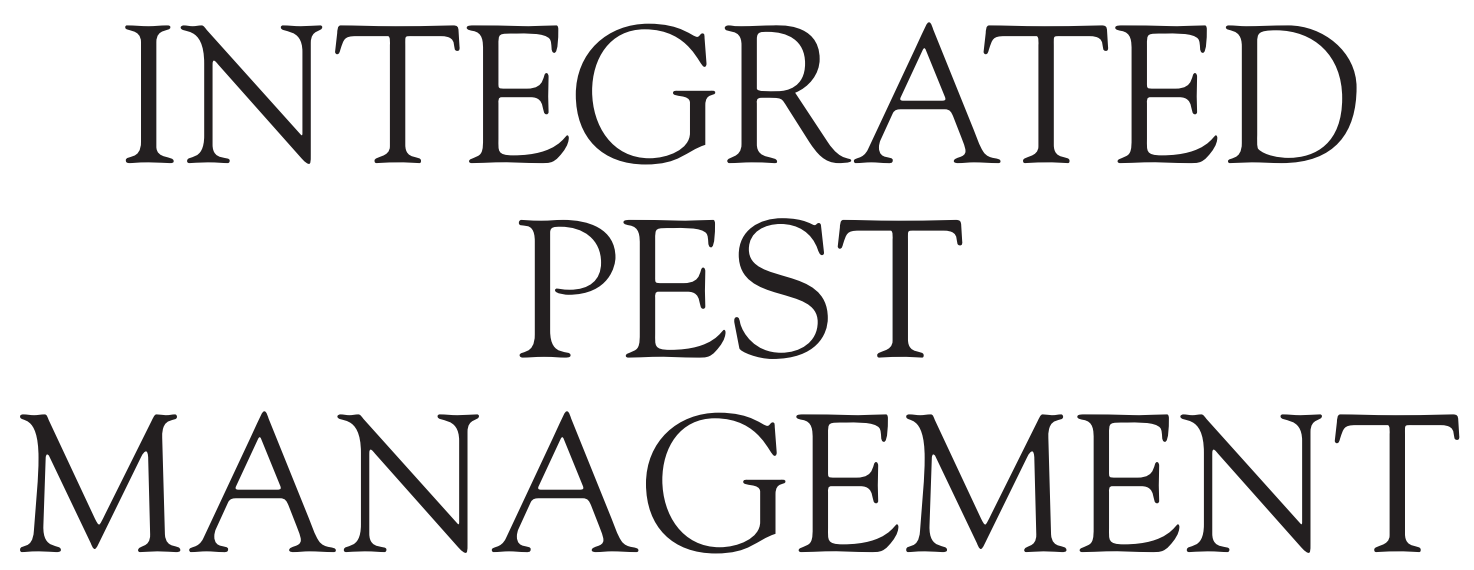

\section{Current Concepts and Ecological Perspective}

Edited by

Dharam P. Abrol 
Academic Press is an imprint of Elsevier

525 B Street, Suite 1900, San Diego, CA 92101-4495, USA

32 Jamestown Road, London NW1 7BY, UK

225 Wyman Street, Waltham, MA 02451, USA

Copyright (c) 2014 Elsevier Inc. All rights reserved.

No part of this publication may be reproduced, stored in a retrieval system, or transmitted in any form or by any means electronic, mechanical, photocopying, recording or otherwise without the prior written permission of the publisher.

Permissions may be sought directly from Elsevier's Science \& Technology Rights Department in Oxford, UK: phone (+44) (0) 1865 843830; fax (+44) (0) 1865 853333;

email: permissions@elsevier.com. Alternatively, visit the Science and Technology Books website at www.elsevierdirect.com/rights for further information.

\section{Notice}

No responsibility is assumed by the publisher for any injury and/or damage to persons or property as a matter of products liability, negligence or otherwise, or from any use or operation of any methods, products, instructions or ideas contained in the material herein. Because of rapid advances in the medical sciences, in particular, independent verification of diagnoses and drug dosages should be made.

British Library Cataloguing-in-Publication Data

A catalogue record for this book is available from the British Library

Library of Congress Cataloging-in-Publication Data

A catalog record for this book is available from the Library of Congress

ISBN: 978-0-12-398529-3

For information on all Academic Press publications visit our website at elsevierdirect.com

Printed and bound in the United States of America

$1415161718 \quad 1098876 \quad 65443321$

- 


\title{
Weather-based Pest Forecasting for Efficient Crop Protection
}

\author{
Rabiu Olatinwo ${ }^{1}$ and Gerrit Hoogenboom ${ }^{2}$ \\ ${ }^{1}$ Louisiana State University, LA, USA, ${ }^{2}$ Washington State University, WA, USA
}

\subsection{INTRODUCTION}

\subsubsection{Crop Protection and Current Challenges}

Although insects, pathogens, mites, nematodes, weeds, vertebrates, and arthropods are different in many ways, they are regarded as pests. They are a major constraint to crop productivity and profitability around the world caused by direct and indirect damage to valuable crops. Insect pests, pathogens, and weeds account for an estimated $45 \%$ of pre- and postharvest losses worldwide (Pimentel, 1991), in addition to losses caused by vertebrate pests (Strand, 2000). Each year, farmers are confronted with several questions and uncertainties on how best to manage potential threats posed by pests to valuable crops, particularly when a significant amount of resources is committed to cultivation and production process, in expectation of profitable yields. Finding ways to address these problems has led to changes in agriculture production systems over the years, with an increase in the use of chemical pesticides to minimize pest damage. However, some unintended consequences, such as emergence of pest resistance due to repeated use of pesticides, mean resurgence of pests and crop damage are still of great concern, in addition to lingering negative effects of pesticide residues on the environment.

These uncertainties have led to pertinent questions such as: What can be done to mitigate the risks caused by disease and pests to valuable crops? Can weather forecasts reliably help predict the risk of disease and pest outbreaks? To what extent can we have forewarning for effective management of pests and diseases with minimal inputs? Are the incidences or severity of these diseases and pests avoidable or predictable? If predictable, can farming practices be improved by incorporating weather information into existing management strategies, for instance to improve the effectiveness of pesticides through minimal and timely applications, to manage pests, but also reduce risks?

Faced with huge risks of crop damage and many uncertainties, farmers need effective and sustainable solutions every season to ensure profitability. This is especially so in many parts of the world where expanding agricultural 
productivity depends on timely, effective, and accurate use of information gathered from multiple sources (including, for example weather forecasts). Weather information is especially critical for making management decisions to avoid or mitigate potential disease and pest outbreaks, improve crop development, and achieve profitable yields.

For a pest attack or disease outbreak to occur, three basic factors must be present; a susceptible host plant, a virulent pathogen or pest, and favourable environmental factors that facilitate disease initiation or pest attack. Favourable weather factors (e.g. temperature, rainfall, wind, relative humidity) may exist within the canopy, on a local scale within the field, or on a regional scale, across several farms. Seasonal variability in weather patterns influenced by preceding or prevailing climatic conditions not only creates a conducive environment for pest population development and distribution, but also influences crop growth and development, and ultimately final yield. Therefore, understanding the delicate balance between host and pest sensitivity to environmental factors such as weather is critical for survival of vulnerable host crops, or a successful attack by aggressive pests or virulent pathogens. Infestations mostly occur when environmental conditions are favourable for initial attack and subsequent interactions with the host. Conducive weather conditions or lack there of, are therefore critical for both pest the population and crop development.

However, since no two growing seasons are the same, extreme weather events driven by climate variability, in addition to increasing global demand for crops, and productivity pressure, have pushed cultivations into regions where conditions are becoming more favourable for invasive pest development, making crops in those regions more predisposed to non-native pest attacks. The ever-expanding worldwide trade and globally increasing demands for food and plant products have also led to crop production pressure, an increase in pests' resistance to pesticides that in the long term may increase pest activities even further, due to intensification of cropping, reduced crop rotation, and increased monoculture (Rosenzweig et al., 2001).

\subsubsection{Weather, Pest, and Crop Interactions}

Whatever the nature of interactions between pests and host crops, weather factors create an additional layer of uncertainty to already complex dynamic interactions between a pest and its host plant. Understanding the nature of this complex interaction requires an interdisciplinary approach to identify critical components needed to develop management tools to address the pest and disease concerns of a farmer. The relationship between two or more organisms within the immediate ecosystem of a crop, in many ways can facilitate the extent of damage caused by a pest, or symptoms observed on host tissues. For example, a warmer than usual condition that favours pest attack may equally favour a competitor, or be conducive for a crop variety to resist attack, whereas reverse conditions such as stress may predispose the same variety to successful attacks by pests or pathogens. However, unfavourable dry conditions may actually be detrimental to both crop growth and pests (e.g. fungal pathogen sporulation).

The dynamic nature of sequences of ecological processes is hard to predict due to many uncertainties inherent in such complex interactions. This complexity and uncertainties, therefore, create opportunities for scientists across different fields to study, understand, and develop management strategies in solving emerging pest problems faced by farmers. Achieving comprehensive integrated management through a multidisciplinary approach is a viable option to mitigate the potential risks of disease or pest epidemics. However, any 
integrated approach starts with examining the three key components individually, i.e. crop, pests, and weather, followed by understanding how the delicate interactions that exist among them could be exploited in mitigating potential threats of pest and disease attacks.

\subsection{WEATHER}

In the past, favourable weather conditions such as warm weather that boosts the pest population, or mild winter temperatures that increase the chance of pest survival through the winter, are known to increase the use of agricultural chemical pesticides, thereby heightening health risks and increasing ecological and economic costs. In the future, extreme weather events from climate variability are expected to contribute directly and indirectly even more to a potential increase in pest damage and the use of chemical pesticides to control the increased pest pressure (Rosenzweig et al., 2001, 2000; Yang and Scherm, 1997).

\subsubsection{Weather Factors and Derived Variables}

Weather variables including temperature, rainfall, and relative humidity, have been tested and reported on extensively in many disease studies (Bailey et al., 1994; Nokes and Young, 1991; Wharton et al., 2008; Olatinwo et al., 2008, 2009, 2010). In some studies, individual computer programs have been developed based on various weather parameters to make predictions, while others studies have incorporated computer programs into commercial advisory equipment ( $\mathrm{Cu}$ and Phipps, 1993; Grichar et al., 2005; Jensen and Boyle, 1965, 1966; Linvill and Drye, 1995; Parvin et al., 1974; Shew et al., 1988; Wu et al., 1999).

Whether excessive, optimal, or insufficient, temperature and rainfall are perhaps the most important variables affecting crop-pest interactions. For example, many pest species favour warm and humid conditions, while moisture stress may cause direct or indirect effects to crop development, making crops more vulnerable to damage by pests, especially at the early stages. Pest infestations often coincide with favourable climatic conditions or weather patterns, such as early or late rains, drought, or increases in humidity, which in themselves can reduce yield.

In most cases, favourable temperature is critical for pest development, population growth, pest epidemics, the extent of damage caused to crops, and the overall crop yield. Cold-blooded pests (i.e. insects) are sensitive to temperature, and therefore insects typically respond to higher temperature, which increases the rate of development and reduces the time between generations. However, very high temperatures may also reduce insect longevity. Warmer winters (mild winters) reduce winterkill of pests through the winter, thereby allowing a greater number of pests to survive through a normally expected harsh winter season, and consequently, increase insect populations in subsequent growing seasons. Rosenzweig et al. (2001) noted that drought resulting from extreme high temperatures and reduced rainfall, changes the physiology of host species, leading to changes in the insects that feed on them, and can reduce populations of friendly insects (such as predators or parasitoids), spiders and birds, and ultimately influences the impact of pest infestations. In addition, abnormally cool, wet conditions can also bring on severe insect and plant pathogen infestations, although excessive soil moisture may drown soil-residing insects.

In addition to temperature and precipitation, relative humidity is another weather variable that has been shown in many studies to be related to the development of fungal pathogens (Damicone et al., 1994; Jensen and Boyle, 1965, 1966; Jewell, 1987; Olatinwo et al., 2008, 2009, 2011; Shew et al., 1988; Wu et al., 1999). In 
monitoring the likelihood of infection initiation through sporulation of fungal spores, the available moisture on a leaf surface can be estimated using relative humidity, since it correlates with wetness of a leaf surface within a canopy. It is a critical component for estimating the likelihood of successful infection initiation and foliar disease development by fungal pathogens (Jensen and Boyle, 1965, 1966). Generally, a relative humidity of $\geq 95 \%$, equivalent to saturation, is assumed to indicate a level of leaf wetness or moisture on the leaf surface sufficient for sporulation and infection initiation on leaf tissue. Although leaf wetness as a weather parameter is rarely measured, a few empirical methods (Matra et al., 2005) have been used to derive leaf wetness durations from meteorological parameters. Dew is another important weather parameter that also influences leaf wetness duration and plays a significant role in facilitating germination of spores and entrance of disease spores into crop tissues (Das et al., 2007).

The infection process of a disease such a Downey mildew (Bremia lectucae) may occur rapidly (i.e. within $48 \mathrm{~h}$ when the leaf wetness requirement is met) to the extent that sufficient time is unavailable for fungicide application or for any meaningful control measure to be taken (Strand, 2000; Scherm and van Bruggen, 1993). Strand (2000) noted that, for such diseases, obtaining leaf wetness and the period of wetting information from weather forecast can provide farmers with sufficient lead-time to take adequate control measures for preventing disease outbreak.

In developing disease and pest models, input variables are not limited to only air temperature, rainfall, and relative humidity, but also include other variables such as wind speed, wind direction, soil temperature, soil moisture, and solar radiation. Depending on pest model needs and knowledge about the biology of a pest of interest or the corresponding host plant, additional weather variables may be required for developing a predictive model. Therefore, measurements of other weather parameters can be obtained by using different techniques and equipment at the field level.

\subsubsection{Critical Weather Variables for Pest Forecasting}

Whether complex or simple, a disease or pest model mostly requires essential environmental variables as inputs to be operational, depending on individual pathogen or pest sensitivity to environmental factors. Access to weather data and derived variables from temperature, rainfall, humidity, and other measurements, is essential for developing, testing, and evaluating these models. For example, models that are based on insect phenology, using derived variables from degree-days accumulation, are more applicable in most environments, since they utilize knowledge about individual pest species and its sensitivity to baseline temperature that correlates with pest population growth. This is usually determined from prior laboratory experiments, field trials, and specific information about the pest biology. For example, Dawidziuk et al. (2012) found that higher winter temperatures could increase the ability of Leptosphaeria maculans and L. biglobosa pseudothecia to discharge ascospores into the air, causing damaging and early plant infections in oilseed rape.

Rainfall patterns (i.e. frequency and intensity) are among the commonly used weather information that is needed for timely scheduling of pesticide applications to prevent pest development or protect crops with signs of early symptoms of a pest attack. In the past, farmers have also used prevailing weather information to modify the microclimate conditions within the canopy (i.e. by lowering the humidity) to reduce the likelihood of infection initiation and disease development (Strand, 2000).

For example, the significance of weather parameters in the development of the thrips 
population has been reported in several studies, including Thrips palmi (McDonald et al., 1998), onion thrips Thrips tabaci (Edelson and Magaro, 1988; Morsello et al., 2008), tobacco thrips (Morsello et al., 2008), and western flower thrips F. occidentalis (Katayama, 1997). The tobacco thrips (Frankliniella fusca Hinds) and the western flower thrips (Frankliniella occidentalis Pergande) are particularly important thrips species that have a significant economic impact on several crops in the southeastern United States (Olatinwo et al., 2008, 2009, 2011). The population peaks of important thrips in field crops and vegetables in the southeastern US mostly occur during the first and second week of May (McPherson et al., 1999; Riley and Pappu, 2000, 2004). Therefore, management decisions such as scouting for pests at weekly (McPherson et al., 1999) or biweekly intervals may be expensive and particularly time consuming, apart from when weather information is available for monitoring population progressions (Olatinwo et al., 2011).

After repeated fungicide applications, many diseases such as leaf spots of peanut may develop resistance to fungicides (Culbreath et al., 2002; Woodward et al., 2010). Monitoring environmental conditions such as rainfall, relative humidity, leaf surface wetness, and temperature to optimize pesticide applications is critical for reducing infection initiation and disease development (Alderman and Beute, 1986; Jensen and Boyle, 1965, 1966; Shew et al., 1988; Wu et al., 1999). Although chemical pesticides are effective tools for managing diseases and pests, they can be inefficient methods for managing pests due to unintended negative impacts on the ecosystems. Constantly monitoring these weather variables are important for delivering an effective pest management strategy, through timely pesticide applications that minimize the overall negative impacts on the environment.

Compared to only 5 or 10 years ago, access to readily available weather information makes many farm management decisions less complicated, especially for disease or pest models that require historical weather data, prevailing weather conditions, and weather forecasts for predicting potential pest risks. However, some gaps still exist in terms of weather data reliability and in translating complex weather information to timely warnings that may significantly reduce the risks associated with pest attacks. With increasing global access to mobile phones, electronic text messages, emails, and dynamic internet website information (i.e. that incorporates weather forecasts into existing pest models) are becoming effective means of instantly communicating pest risk information to farmers. To earn the trust of end-users, the uncertainty inherent in pest models and weather forecasts used in generating a risk alert must be addressed and concisely presented to users, since the accuracy and reliability of disseminated risk information are critical for management decisions and adoption of such products.

Apart from the general weather forecasts, which are limited to the meteorological elements and factors such as maximum and minimum temperature, type, duration and amount of precipitation, cloudiness, and wind speed and direction, there are other types of forecast (Das et al., 2007) that might be useful depending on the required range of the forecast. These include the nowcasting and very short-range forecasts, the short- and medium-range forecasts, and the long-range forecasts. Whatever the type or source of weather data, reliability is crucial.

\subsubsection{Sources of Weather Data and Reliability}

Weather information is available from several sources, including from national governments such as in the US, the National Weather Service (NWS; http://www.weather.gov/) or automated weather networks that are managed by Land Grant Universities, such as the Georgia Automated Environmental Monitoring 
4. WEATHER-BASED PEST FORECASTING FOR EFFICIENT CROP PROTECTION

Network (AEMN; www.Georgiaweather. net), one of the largest automated weather station networks in the southeastern USA (Hoogenboom, 2000, 2001; Hoogenboom et al., 2003) and AgWeatherNet, managed by Washington State University (www.weather. wsu.edu). In some cases, weather data from some regional networks have been integrated with pest prediction models, as demonstrated by the NSCU-APHIS Plant Pest Forecasting (NAPPFAST) system (Magarey et al., 2007). Therefore, it is not surprising to see automated weather stations becoming more available to complement other sources of weather data for implementing pest predictive models. However, spatial resolutions of the weather data sources for most of the existing pest forecast models are coarse due to insufficient coverage by the monitoring stations. With the rapid advancement of technology in agriculture, there is a growing need for customized local weather forecasts to enhance pest and crop production decisions at a local farm level.

Strand (2000) noted that improved technology has made automated weather stations more accessible; in particular, the availability of internet services, mobile phone applications, and other portable hand-held devices is making data from such stations even more accessible to farmers and stakeholders. In fact, several regional networks of automated weather stations including AgWeatherNet (http: / / weather. wsu.edu/awn.php), Georgia Automated Environmental Monitoring Network (http:// www.georgiaweather.net/), North Dakota Agricultural Weather Network (http://ndawn. ndsu.nodak.edu/), and many others are now available. However, some limitations still exist on the type of weather data available. Also, due to limitations in spatial coverage by existing networks, it is impossible to obtain farm-specific forecasts or measurements for monitoring biological processes (pests and diseases) on a specific field scale or within the crop canopy at every farm in a region, if such parameters are need for making pest predictions.

The distance from a farm location where weather information is needed for making management decisions, to the nearest station on the weather network may play a critical role in pest prediction accuracy. Available data through the station may not accurately represent the current weather conditions on a farm that is perhaps 10-20 miles away, yet it could be the nearest and only source of weather information available for making meaningful management decisions at the field level. However, the accuracy of on-farm measurements could be improved by developing correlations or statistical relationships between measurements in the field and data from the nearest stations of an automated weather station network. This type of technique may enhance pest prediction accuracy and integration of weather information into farm management schemes (Strand, 2000; Weiss, 1990). Weather variables also play a crucial role as inputs in models for predicting insect vector/pathogen population dynamics. For instance, weather patterns were shown to have a significant but indirect effect on the incidence of Tomato spotted wilt virus transmitted by thrips in peanut (Olatinwo et al., 2008, 2009). Several studies have also used weather parameters as a management tool for monitoring pests/vectors and diseases/pathogens in valuable crops (De Wolf and Isard, 2007; Magarey et al., 2007; Wharton et al., 2008). However, innovative approaches to weather forecasts are also emerging.

The Weather Research and Forecasting (WRF: http://www.wrf-model.org) model is a next-generation mesoscale numerical weather prediction system designed to serve both operational forecasting and atmospheric research needs. The WRF model developed by the National Center for Atmospheric Research (NCAR) features multiple dynamical cores, a three-dimensional variational (3DVAR) data 
assimilation system, and a software architecture allowing for computational parallelism and system extensibility. The WRF model is suitable for a broad spectrum of applications across scales ranging from metres to thousands of kilometres. Potential applications of WRF in plant disease and insect vectors were recently evaluated (Olatinwo et al., 2011, 2012), of which two examples are discussed as case studies later in this chapter.

Implementing a disease or pest model requires easy access to reliable sources of weather data, and knowledge of the pest and host crop. Although several weather parameters may be required, as mentioned earlier, the key inputs from weather measurements mostly include temperature, rainfall, and relative humidity. Since not all inputs needed for developing a model are available through the standard weather station data, other variables that are not measured are either calculated, computed, or derived from actual weather measurements. Usually, this is done by using tested algorithms, statistical analyses, and mathematical functions in calculating new derived variables. A good example is leaf wetness (i.e. the wetness of a leaf surface) that can be estimated from the relative humidity as mentioned earlier. Derived variables are extremely important when instruments for measuring the variables are limited or impossible to deploy for collecting reliable data. Therefore, in this case, the leaf wetness can be estimated from relative humidity measurements from the local weather station to help determine the likelihood of sporulation of fungal pathogens on a leaf surface. The data from regional scale weather monitoring networks obtained from different sources is as important in monitoring pest outbreaks as the on-farm measurements of weather parameters for monitoring disease or pest development within the canopy. A regional-scale weather forecast is a useful source of data input for disease and pest models, and is needed for monitoring disease epidemiology and pest population dynamics on a larger scale.

\subsection{PESTS}

\subsubsection{Sensitivity and Vulnerability to Weather Factors - Extreme Events and Prevailing Climate}

Sensitivity of pests to temperature and rainfall usually varies by species. Extreme weather conditions such as high temperatures, low temperatures, a decrease in precipitation, or extreme flooding could have direct effects on pests and crops, while host crops (depending on individual variety) may be indirectly affected through weather influences on soil processes, nutrient dynamics, and abiotic stressors that predispose crops to disease and pest attacks. Ultimately, variability in temporal and spatial weather conditions due to shortand long-term climate variability could have an impact on soil conditions, water availability, agricultural yield, and susceptibility of crops to pest and pathogen infestations (Rosenzweig et al., 2001).

The USPEST.org (http://uspest.org/wea/) is an Integrated Pest Management (IPM) model and forecasting web resource for agricultural, pest management, and plant biosecurity decision support in the US. The internet site provides over 78 degree-day and 18 hourly weather-driven models serving many IPM, regulatory, and plant biosecurity uses in the United States and specializes in IPM needs for the Pacific Northwest, according to available information on the site. Degree-day data presented on the site are very useful for monitoring pest developments and prevailing weather conditions, and in evaluating different options available for management through the growing season. Models developed based on a simple technique of degree-days, may utilize air or 
soil temperatures to describe the phenology of an individual pest, and helps determine when they reach a pre-determined population threshold that would warrant pest management actions. The information may also be useful for scheduling pesticides application based on known biology of the pest. Strand (2000) noted that the degree-days technique has been useful for controlling insect pest populations, such as the European corn borer, rice water weevil, and pink bollworm, particularly in tree, vegetable, and field crops, where pesticide applications may be accurately timed using phenology models.

According to Rosenzweig et al. (2001, 2000), and Yang and Scherm (1997), mild winter weather or other extreme events such as abnormally high summer temperatures are expected to increase in frequency, and may directly or indirectly contribute to increase the risk of pest damage in the near future. Currently, there are few examples of known pests of valuable crops other than soybean cyst nematode (Heterodera glycines) and sudden death syndrome (Fusarium solani f. sp. glycines) that have recently expanded their geographical ranges due to more favorable conditions for development (Hartman et al., 1995; Rosenzweig et al., 2000; Roy et al., 1997). The dynamic nature (i.e. expanding or shrinking) of geographical ranges of several important insects may accelerate with changing global climate, resulting in gradual expansion of the reach of pests beyond the traditional ranges we currently know. Matching this shift with early detection methods and effective management strategies to deal with potential threats from invasive pests shifting beyond known ranges into a new geographical region will be critical. Seasonal pest monitoring efforts may be strengthened by using weather forecasts that provide forewarning information and a scouting guide for locating areas where favourable conditions are met and impending pest population increases or emergencies are expected.

\subsubsection{Weather Forecasts for Early Warning/Scouting of Pest}

Detecting an impending disease outbreak or pest attack early enough by itself serves as a strong management tool. According to Das et al. (2007), 'the projections for optimum flight periods from daily synoptic weather forecasts facilitate the detection of invasions of pest and disease vectors and also the timing of pesticide applications to intercept and eliminate pest infestations during displacement from breeding areas.' Since the cost of pesticide application constitutes a sizeable amount of a farmer's total overall cost during a given crop production season, minimizing the use of agrochemicals will likely make more cash resources available to a farmer by reducing the overall costs needed to increase the acreage that is protected against pests or diseases. It will also free-up resources to provide additional plant nutrition needed to increase crop productivity, while reducing environmental contamination from chemical residues. In view of this, the use of weather forecasts in predictive models for early warning of an impending attack, scouting of insects, or early detection of diseases and weeds, can not only help minimize the volume of agrochemicals applied, but also make the applications more effective. It will prevent overuse of chemical pesticides and reduce the development of chemo-resistant strains of pests and pathogens (Das et al., 2007).

A carefully evaluated disease model coupled with the weather forecasts from WRF output as discussed later in this chapter could provide an approach for routine spatiotemporal predictions of potential threats for many diseases of valuable crops, especially those for which IPM can play an important role in the long term. The easy to understand spatiotemporal distribution map would provide growers with a simple to understand warning and ample time to take preventative measures in protecting high value crops. 


\subsection{CROPS}

\subsubsection{Agronomic Dependence on Weather Factors - Planting Days, Phenology, and Host Maturity}

Genotypic and phenotypic traits of a crop can make it either vulnerable or resistant to pest attack. Susceptibility of a crop to weatherinduced stresses, and infestations or infections caused by pests or diseases, vary among crops, among different varieties within the same crop, and among different growth stages within the same crop variety (Das et al., 2007). Over the years, crop breeders have selected several traits in breeding programmes (depending on the crop), to meet consumer expectation, to address crop vulnerability to pests and diseases, to improve productivity, and increase profitability. These needs led to intermittent releases of improved crop varieties that differ in many ways, ranging from attributes such as maturity (early or late), yields (high or low), how sensitive or tolerant they are to environmental factors (such as drought), and how susceptible they are to pathogens and pest attack (resistance or susceptible).

Availability of different crop varieties with varying levels of sensitivity to pests makes variety selection decisions by farmers a critical component of any IPM approach. It provides farmers with a decision tool for pest management. For example, selecting an early maturing variety may be uniquely suitable for cultivating a crop at a specific period, to avoid diseases or insect pest attacks during the latter part of the growing season as a management strategy. In view of this, for an IPM strategy, weather forecasts (i.e. temperature) serve as a useful means to monitor crop phenology effectively, estimate crop growth and development, and quantify changes under varying environmental conditions through the growing season. Accumulation of average daily temperature above a pre-determined base temperature (degree-days; unique to individual species) is a common and simple technique that has been used in the past for monitoring crop development and insect pest phenology.

The cropping systems model (Strand, 2000) is a more comprehensive approach that utilizes complex mathematical equations, incorporated with weather parameters (air and soil temperature, rainfall, etc.,) and derived variables including degree-days, to generate information on the status of crops, their pests, and potential threats under multiple scenarios, and probable management options. Although there are few examples of cropping system models, some have been developed into products with pest models as an optional module in the management decision process (Boote et al., 1983; Jones et al., 2003). Overall, an important benefit of this type of model is that it allows simultaneous evaluations of interactions between crop and pest components, potentially providing a farmer with more in-depth information needed to improve overall crop-pest management decisions (Tsuji et al., 1998).

\subsubsection{Synchronization of Pest Emergence and Host Development; Avoidance and Planting Dates}

Whether it is traditional or genetically improved crop varieties, both are critically sensitive to environment factors such as changing weather patterns. Although drought-tolerant varieties of various crops are mostly available to farmers, many varieties are still prone to infections or infestations under stressful environmental conditions such as drought or flooding. Manipulating planting dates, i.e. planting early or late, or planting an early- or latematuring variety, coupled with weather forecasts, is an approach that farmers can exploit to avoid population peaks of pests or insect vectors, thereby lowering the probability of host vulnerability and risk of potential attack (Strand, 2000). 
Olatinwo et al. $(2008,2009)$ described the synchronization of peanut planting date and early populations of thrips as critical components in managing Tomato spotted wilt virus in the southeastern US. Like several other soilborne pathogens, development of sugar beet cyst nematode (Heterodera schachtii) is quite sensitive to changes in soil temperature, and therefore its population in the soil is usually measured using degree-days based on soil temperature. Studies (Olatinwo et al., 2006a,b,c), have exploited this sensitivity in monitoring progression of sugar beet cyst nematode generations in greenhouse experiments and in vegetable fields during the growing season. Roberts and Thomason (1981) indicated how early plantings of sugar beet could take advantage of cooler temperature when $H$. schachtii nematode is inactive and unable to attack due to temperature conditions that are below the required base threshold for development. Therefore, selecting the most suitable variety (i.e. at the beginning of the season) based on variety phenology and seasonal weather forecasts or prevailing weather conditions may strengthen a farmer's ability to manage pest attack effectively within an IPM approach.

Weather factors influence insect occurrence and govern the general distribution and numbers of insects, and, therefore, can either foster or suppress insect life. Das et al. (2007) noted that temperature and relative humidity control the time interval between successive generations of insects as well as the numbers produced in each generation, while wind patterns are an important factor for the migration of insect pests. Strand (2000) also noted that frequent and heavy rainfall characterized by runoff and flooding could serve as an impetus for conducive and suitable habitats for locust survival and population growth. A study by Prior and Streett (1997) on strategies for the use of entomopathogens in the control of the desert locust found that, although preventing locust outbreaks by destroying flightless nymphs (which can be monitored using weather information) might be desirable, emergency measures are usually preferred to control the destructive swarms of desert locust adults.

Interactions involving crops, pests and the environment can be very complex to untangle. However, almost all components of an IPM strategy including variety, biological control agents, planting date, crop rotation and other cultural practices are either directly or indirectly affected by environmental factors such as changing weather patterns or climate variability. For example, a crop variety might not do well under extreme weather conditions, or a biological control agent might be less effective and out-competed by targeted pest if the environmental conditions are unfavourable for it to establish. A planting date might be too early or too late if soil temperature is not suitable for planting. Even the amount of moisture on plant surfaces and wind speed/direction might affect uptake and coverage of pesticide applications, respectively. Hence, environmental limitations to any of these factors could have serious constraints for effective and successful implementation of IPM methods, and, thus, efforts to control diseases and pests of valuable crops at critical periods during the growing season.

\subsection{EFFICIENT CROP PROTECTION PRODUCT}

\subsubsection{Weather-Based Forecasts and IPM}

IPM is a crop production technique that is generally accepted as an effective strategy for balancing between management of pests using a minimum amount of chemical pesticides and reducing the negative impacts of pesticide applications on the environment. It is fast becoming a favoured approach in many regions across the world because it combines multiple management techniques including use of resistant varieties, a natural enemy, and 
biological control agents, improved cropping practices such as crop rotation, tillage, and irrigation methods, and a minimal amount of pesticide use, based on weather forecasts and timely applications of pesticides. As part of an IPM, weather information is critical for selecting the most suitable variety (i.e. early or late maturing, according to phenology), and the best planting date(s) to avoid diseases or pest pressure at an early stage of crop development. Hence, IPM provides farmers with a variety of choices to plan and take preventative measures against disease development and pest attacks from pre-planting throughout the growing season until final harvest.

Scientific and technological advances in biotechnology, agro-meteorology, and computer science are complementing traditional methods of pest management with newer and more efficient techniques that have produced transgenic resistant varieties, high-resolution weather forecasts, and accurate pest predictive models. Where IPM has been implemented, it has demonstrated that both emerging technologies and traditional pest management methods can be complementary to each other in preventing threats posed by pests to valuable crops. Profitable and efficient crop production is achievable with IPM techniques, while minimizing the impacts of chemical pesticides and fertilizer inputs on the environment.

In addition to the use of chemical pesticides to improve crop productivity, selecting a resistant variety that can tolerate or resist pathogens or pest attacks is not only good for the environment, but also relatively inexpensive compared to pesticide applications alone. Generally, resistance expressed by a crop variety is a product of genetic traits of that variety, the virulence of the corresponding pathogen or pest, and how they interact with other components such as weather, soils, and cultural practices within the environment. Genetic engineering and biotechnology have so far played a significant role as tools in crop improvement, turning out new cultivars each year to address crop production needs. They have improved and complemented the traditional crop breeding methods, through relatively quick gene transfer techniques that have resulted in new varieties with desirable traits against potential impacts of pests and diseases. A good example is genetically engineered corn carrying bacteria (Bacillus thuringiensis) endotoxin gene, which makes it tolerant to insect attacks.

Strand (2000) alluded to other examples such as genetically engineered carrots with antifungal genes from tobacco that offer protection against powdery mildew. In some cases, crops are engineered to tolerate herbicide applications, while competitive weeds at the target site are killed. This type of crop improvement (resistant host crop) provides farmers with another tool to fight pest attacks, in addition to the use of weather information for short-term monitoring of pests. However, a sudden breakdown in crop resistance to a pathogen or a pest due to frequent use of pesticides may be catastrophic for overall crop production. Resistance to a single pest or disease may be less effective when multiple pests are involved, but perhaps more effective when used in combination with other techniques and as one of the components of an IPM approach.

Apart from increasing pest resistance to pesticides due to repeated use, there are other negative impacts of chemical residues on the ecosystems, including contamination of surface and groundwater, and beneficial organisms. Hence, strategies for managing pests by farmers will continue to shift to an integrated management approach that reduces both the frequency and the amount of chemical applications released into the environment. IPM is a viable option the farmer can explore and be improved upon every year through precise and timely applications of pesticides. With significant progress made in the field of science and technology, pest models have been coupled with high-resolution weather forecast data to 
predict the risk of an impending increase in pest populations or favourable conditions for infection initiation and disease development. Olatinwo et al. (2011, 2012) recently examined the application of this promising scientific approach for managing insect vectors and a peanut disease in the southeastern United States. The disease and insect vector models were coupled with the weather predictions or forecasts provided by the WRF model. A part of this study (Olatinwo et al., 2012) evaluated a potential short-range forewarning concept that triggers an alert and generates a $3 \times 3 \mathrm{~km}$ grid high-resolution map when a favourable condition for the potential onset of a disease is met.

\subsubsection{Existing Products}

How farmers consume weather forecast information is by itself important. Several webbased pest models that are driven by weather information can now deliver location-specific risk alerts using simple web graphics. Most existing internet-based interactive systems/ models can output spatial and temporal distribution maps to depict the potential level of pest risks which is easy enough for farmers or stakeholders to understand and incorporate into a quick decision process for monitoring the likelihood of a pest outbreak. Measurements and observations from regional weather networks are coupled with disease and pest prediction models, while online maps are generated and frequently updated on a regional scale, for monitoring likelihood of infections or outbreaks in valuable crops. Examples of internetbased interactive systems include the potato late blight in Michigan (http:/ / www.lateblight. org/forecasting.php) described by Wharton et al. (2008); the AWIS Weather Services, Inc (http://awis.com); the Oklahoma mesonet peanut leaf spot advisor (http://www.mesonet.org/index.php/agriculture/category / crop/peanut/leaf_spot_advisor) based on a model described by Damicone et al. (1994);
North American Plant Disease Forecast Center, North Carolina State University (http://cdm. ipmpipe.org/); HortPlus (http://www.hortplus.com/Brochure/MetWatch/MWSoftware. htm); and a web-based tool for Fusarium Head Blight risk assessment (http:/ / www.wheatscab. psu.edu). AgWeatherNet also incorporates several disease models for cherry and grass for the state of Washington, USA (www.weather. wsu.edu). These web-based IPM risk assessment tools usually generate distribution maps that are very easy to understand and useful for monitoring the potential level of risks across a given area. Generally, they are models that have been developed based on an in-depth understanding of how weather factors affect biology and development of a particular pest and evaluated with local data.

The University of California, Davis also developed an online database of IPM models (http://www.ipm.ucdavis.edu/WEATHER/ index.html) from a large collection of research summaries of phenology models for insects, mites, diseases, plants, and beneficial organisms. This internet-based interactive system is a useful source of information on key weather parameters that are needed as input for designing a successful IPM strategy that improves crop productivity. In addition to local weather conditions, some systems also include parameters such as type of soil, type of crop, and phenological stages, as well as level and type of insect pest infestation. Usually, a combination of these parameters is considered in offering advisories for decision-making on sowing, harvesting, irrigation, nutrient management, and chemical application (Dacom, 2003).

A typical internet weather-based pest forecasting web site frequently updates predictions or risk assessments using the most recent weather data (depending on parameters) available as input. The output/predictions, in most cases, are translated into simple management recommendations that farmers can use in deciding what action is needed, if any. Seeley 
(2002) noted that insect and disease control, pheromone release, irrigation, freeze prevention, maturity indices, and fruit damage have benefited from weather database prediction programs. This is largely due to the significant improvement in computer technologies that deliver new tools, and increasing accessibility to information disseminated through media such as the internet and cell phones using push technology.

\subsubsection{Case Studies}

We examined two case studies on the significance of weather-based pest forecasting for efficient peanut protection in Georgia, USA. The early leaf spot disease of peanut caused by a fungal pathogen, and the Tomato spotted wilt virus (TSWV) of peanut transmitted by two major thrips vectors, were examined as examples of complex pathogen-vector interactions. The two case studies explored the potential application of the high-resolution WRF model, which is a next-generation mesoscale numerical weather prediction system designed to serve both operational forecasting and atmospheric research needs (Prabha and Hoogenboom, 2008).

\subsubsection{Case Study 1: WRF model and Early Leaf Spot in Peanut}

Cercospora arachidicola S. Hori is a major fungal pathogen that causes early leaf spot in peanut (Arachis hypogaea L.), a devastating foliar disease of peanut that can result in complete defoliation of susceptible peanut cultivars. The disease accounts for significant yield losses in the absence of fungicide applications (Cantonwine et al., 2006), and it is a major problem for peanut production in the southeastern United States, mostly resulting from inadequate and untimely applications of fungicides. In Georgia, losses due to peanut leaf spot diseases were approximately $\$ 42$ million in 2005 (Kemerait, 2006). Generally, symptoms of infection typically appear in the lower canopy and later progress to the upper canopy. Economic losses can increase significantly from ineffective monitoring where timely management of leaf spot is required (Jacobi et al., 1995a,b; Woodward et al., 2010).

Although applications of fungicide remain an effective tool for managing leaf spot in peanut, Culbreath et al. (2002) and Woodward et al. (2010) noted that repeated applications of fungicides can lead to risks of fungal pathogen resistance. Therefore, timely and effective management of the disease rely on good monitoring of environmental conditions, i.e. rainfall, relative humidity, leaf wetness, and temperature, which are required for infection to occur (Alderman and Beute, 1986; Jensen and Boyle, 1965, 1966; Shew et al., 1988; Wu et al., 1999).

For early leaf spot, weather information is crucial for developing prediction models $(\mathrm{Cu}$ and Phipps, 1993; Linvill and Drye, 1995), especially for monitoring favourable conditions for disease development on host crops during the growing season. Jewell (1987) identified a strong correlation between early leaf spot incidence and cumulative hours of relative humidity ( $\mathrm{RH} \geq 95)$. The Oklahoma peanut leaf spot model described by Damicone et al. (1994) calculates the daily 'infection hours' based on $24 \mathrm{~h}$ of temperature, and leaf wetness or relative humidity. According to Grichar et al. (2005), other systems have used a similar combination of relative humidity/leaf wetness and temperature to forecast favourable conditions for disease development and scheduling of fungicide applications.

Olatinwo et al. (2012) demonstrated the possibility of coupling the high-resolution WRF data output with a leaf spot disease model, i.e. Oklahoma peanut leaf spot model in predicting favourable conditions for early leaf spot infection. The spatial-temporal distribution maps of infection threats generated from the coupled models highlighted the usefulness of the approach. Maps of areas identified as having 
favourable conditions for the disease could complement field scouting for early leaf spot symptoms and for timely applications of management measures. The coupled model output (risks distribution maps) is particularly useful at the beginning of the growing season when management decisions are taken at critical peanut development phases.

The spatial and temporal distribution probability of leaf spot occurrence (Figure 4.1) showed that peanut fields in southeast Georgia and the coastal areas would be more vulnerable to leaf spot risk due to favourable weather conditions during the period evaluated. The infection hours required for leaf spot development from the coupled models increased along the coastal areas where the required optimum number of infection hours (36h) was met earlier, compared to southwest and central Georgia. The probability of favourable conditions for infection was $0.8-0.9$ along the coastal areas. After several days, the trend extended to the southwest and central parts of Georgia during the evaluated period of this study.

It is important to note that the disease model used the prevailing variability in weather conditions for each grid location, i.e. $3 \times 3 \mathrm{~km}$ grid to produce the distribution map, which could assist farmers with timely applications, rather than using a pre-determined traditional spray calendar, which does not take into account the prevailing weather conditions during the growing season. The alert of favourable conditions for the potential onset of early leaf spot at a resolution of $3 \times 3 \mathrm{~km}$ grid was demonstrated in the study (Figure 4.1). Developing an early warning tool based on the approach would be useful for locations where weather stations are currently not available. The spatiotemporal distribution could be produced by coupling the two models, i.e. WRF and the Oklahoma peanut leaf spot model. This could be useful by itself or complement existing tools for disease management activities such as scheduling of fungicide applications.

\subsubsection{Case Study 2: WRF Model and Thrips-Vector Populations}

Several million dollars in crop damage are reported annually due to infestations of tobacco thrips (Frankliniella fusca Hinds) and western flower thrips (Frankliniella occidentalis Pergande), which are economical pests of valuable crops such as cotton (Gossypium hirsutum L.) and peanut (A. hypogaea L.). Both thrips are also important vectors that transmit TSWV to field crops, ornamentals, and vegetables (Olatinwo et al., 2008). As with many insect pests, the populations of both thrips species are sensitive to changes in seasonal temperature. The population growth relies on favourable weather conditions such as prolonged temperatures above a minimum developmental threshold (i.e. base temperature) during the season. Therefore, access to accurate weather information is critical for predicting thrips' population dynamics during early spring when thrips' population information could assist farmers in mitigating damage to crops.

Among many factors, Lewis (1997) noted that the thrips' infestation of a crop depends on favourable weather conditions for population growth, while several studies (Brown et al., 2005a,b; Chaisuekul and Riley, 2005; Harding, 1961; McDonald et al., 1998) have linked rainfall patterns and temperature to thrips vectors and spotted wilt development. Heavy rainfall was reported to have a negative effect on thrips' larvae survival (Kirk, 1997) and adult flight (Lewis, 1997), while increased temperatures during the spring were associated with greater thrips' activity and population growth (Kirk, 1997; Lewis, 1997; Lowry et al., 1992; Pearsall and Myers, 2001). Harding (1961) suggested that cool temperatures and rains are detrimental to thrips' colonization on onions in south Texas. Thrips often migrate into cropping fields during the spring after overwintering on uncultivated plants or alternative hosts (Groves et al., 2002, 2003; Kirk, 1997; Lewis, 1997; Pearsall 

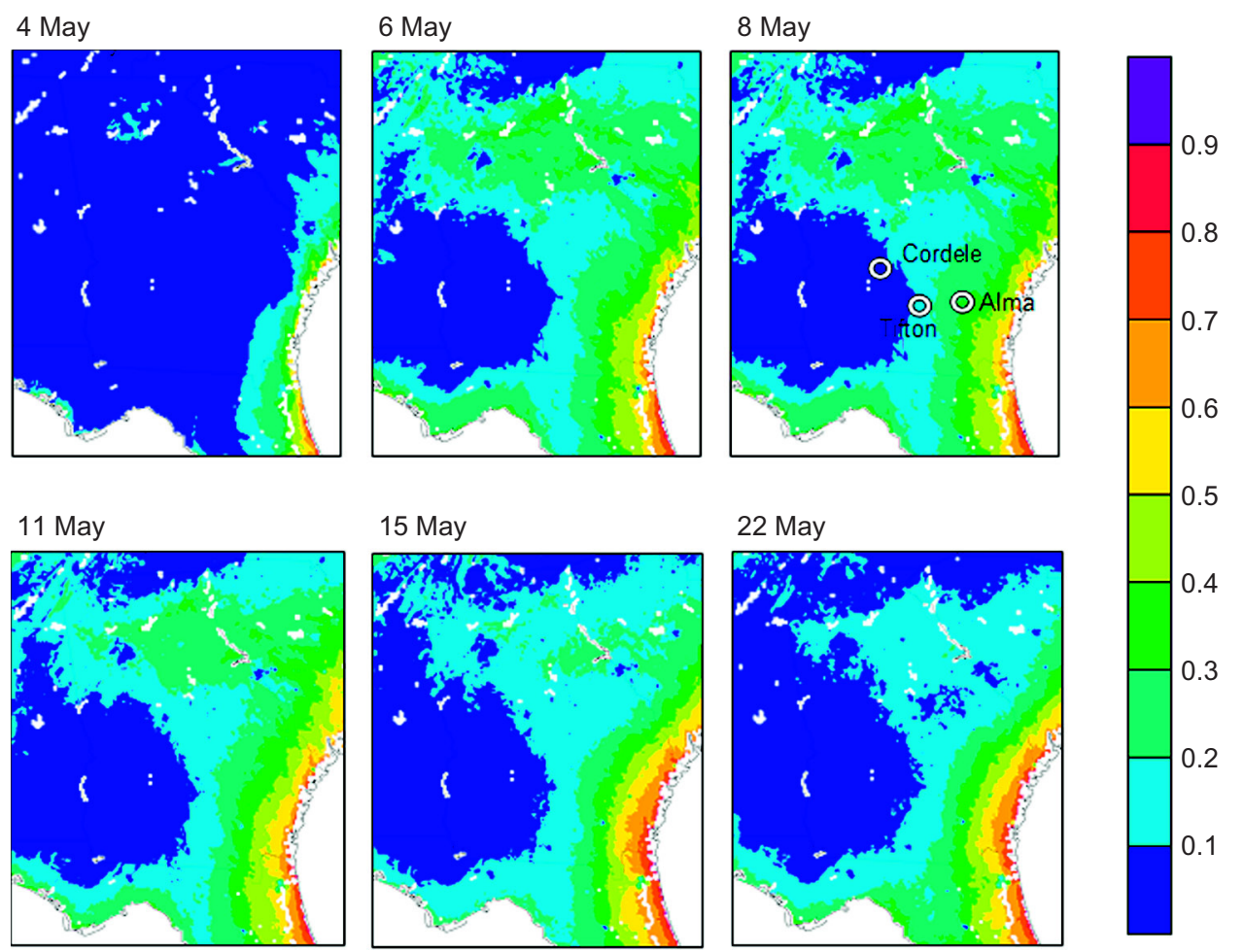

FIGURE 4.1 Spatiotemporal distribution of the probability of occurrence of early leaf spot of peanut (Arachis hypogaea L.), a disease caused by Cercospora arachidicola S. Hori, during the period from 4 May to 22 May 2007 for Georgia, USA (Olatinwo et al., 2012).

and Myers, 2001). Hence, the timing of peanut emergence in relation to the movement of viruliferous thrips vectors into a cultivated field can significantly affect the incidence of TSWV for the remainder of the season (Culbreath et al., 2003).

Olatinwo et al. $(2008,2009)$ noted a high probability of spotted wilt if the number of rain days during March was greater than or equal to 10 days and planting was before 11 May or after 5 June. The total evapotranspiration in April and the average daily minimum temperature in March similarly increased the risk of spotted wilt. Knowing in advance the level of spotted wilt risk expected in a peanut field could assist growers with evaluating management options and significantly improve the impact of their decisions against spotted wilt risk in peanut (Brown et al., 2005a, 2008; Olatinwo et al., 2010).

Stormy weather conditions have been linked to mass flights of thrips. Weather fronts and incipient thunderstorms are reported to discourage the mass flight of thrips, thereby resulting in high densities above the soil surface due to the landing attempts of thrips (Kirk, 2004; Lewis, 1964, 1965, 1973, 1997), while Morsello et al. (2008) also found that the number of thrips captured in flight has a positive relationship with the number of wet days or days with precipitation. In peanut, populations of adult thrips vectors F. occidentalis and F. fusca were reported to be greater for early planting 
in April or late planting in June compared to planting in May (Mitchell and Smith, 1991; Todd et al., 1995). Field observations also indicate a higher level of spotted wilt associated with early- and late-planted peanuts compared to those planted during the middle of the planting season (Brown et al., 2005b, 2008; Olatinwo et al., 2008).

Studies (Kirk, 1997; Lewis, 1997; Lowry et al., 1992; Pearsall and Myers, 2001) have shown that a higher thrips activity and population growth are linked to an increase in temperature during the spring, while Morsello (2007) and Morsello et al. (2008) found that the numbers of F. fusca captured in flight was positively related to degree-days. Olatinwo et al. $(2008,2009)$ evaluated potential application of the WRF model in developing high-resolution spatial and temporal distribution maps of favourable conditions for thrips' development. Results based on degree-day models showed that southwestern Georgia is more favourable for thrips' development during the early part of the growing season examined, with a varied rate of development according to thrips species (Figure 4.2). The high-resolution forecasts map of favourable conditions could serve as a scouting guide in places where weather information is limited, thereby assisting growers in pest management decisions and timely application of pesticides.

\subsubsection{Accuracy, Limitations, and Uncertainties}

Initially, computational resource requirements for running the high-resolution weather WRF model were a great challenge in the implementation of this approach. However, computational limitations and access to highresolution weather data are no longer major constraints compared to earlier years. A 3-day forecast range of high-resolution disease prediction based on WRF forecast data is achievable and now possible (Olatinwo et al., 2011, 2012). For thrips, the degree-day accumulation demonstrated the potential application of WRF in pest management, although Olatinwo et al. (2011) noted that degree-day calculation alone does not necessarily translate to the exact changes in population of thrips. Depending on the individual pest model, several biotic and abiotic factors may still be necessary to be able to estimate the population accurately.

Growers can incorporate model predictions into a decision support system for routine disease or pest management decisions. The traditional spray scheduling of fungicide applications by growers as a preventative means of controlling many diseases of valuable crops such as leaf spots, usually calls for intermittent pesticide applications at a regular intervals (e.g. 15 days through the season), irrespective of incidence or severity of a disease or pest population pressure. Olatinwo et al. (2011) observed that the traditional approach generally does not consider weather factors in scheduling pesticide applications, except for avoiding rainfall or other factors that could hinder the pesticide application process. However, spraying at intervals irrespective of disease or pest biology, may lead to unnecessary sprays that have the potential to leave behind a high amount of chemical pesticide residue harmful to the environment.

Developing weather-based forecasting for efficient crop protection is, therefore, not only necessary, but the implementation of the approach is obviously dependent on several factors for it to be successful and operational. Some crops require an in-depth understanding of biological processes and extensive studies on pests of interest, to identify and accurately measure the parameters needed for quantitative forecasts, while additional knowledge and research may be required for others. Overall, there are uncertainties inherent in the biotic or abiotic parameters that are needed for qualitative forecasts or accurate predictions. The extent of these uncertainties could significantly affect the accuracy of a model, creating an unreliable assessment of pest populations and potential risks 


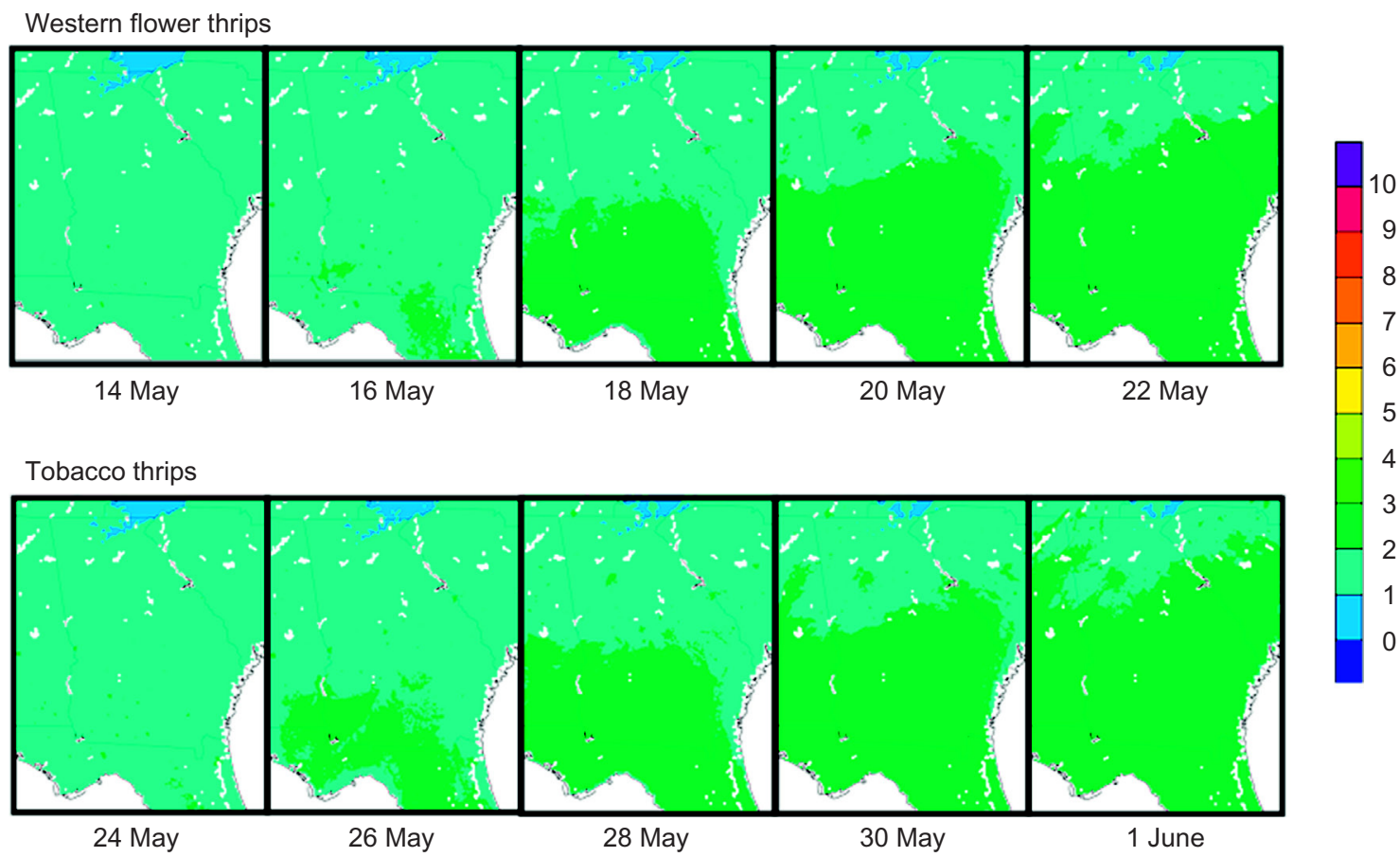

FIGURE 4.2 Spatial and temporal distribution of potential thrips accumulated generations in the southeastern United States using predictions from the Weather Research and Forecasting (WRF) model and the base temperature requirement for tobacco thrips (Frankliniella fusca) and western flower thrips (Frankliniella occidentalis) for 2007 (Olatinwo et al., 2011).

of crop damage, which could complicate farmers' decisions on suitable management options. Therefore, in addition to reliable weather forecasts and thorough knowledge of a disease or pest required to develop predictive models, evaluating predictions from such models with actual field observations is a cautious and critical step required in the process, as it provides an added level of confidence to end-users in terms of accuracy of the model.

\subsection{CONCLUSIONS}

The threat of a disease epidemic or pest outbreak is real; hence constant monitoring is required to avert risks of significant damage to valuable crops from one year to the next.
Therefore, accurate and reliable weather-based pest forecasting remains a critical component in current and emerging IPM strategies. It is not only important to protect valuable crops, improve crop productivity, or increase economic returns for farmers, but also vital for efficient use of pesticides and overall protection of the environment. Obviously, there are several uncertainties inherent in using weather parameters for disease/pest forecasts. However, as our knowledge on the biology of individual diseases or pests improves through new scientific findings and application of emerging technologies in fields such as computing and statistics, the accuracy of weather-based pest forecasts is expected to become a lot more reliable in the future, thereby enhancing successful implementation of long-term IPM strategies. 


\section{References}

Alderman, S.C., Beute, M.K., 1986. Influence of temperature and moisture on germination and germ tube elongation of Cercospora arachidicola. Phytopathology 76, 715-719.

Bailey, J.E., Johnson, G.L., Toth, S.J., 1994. Evolution of weather-based peanut leaf spot spray advisory in North Carolina. Plant Dis. 78, 530-535.

Boote, K.J., Jones, J.W., Mishoe, J.W., Berger, R.D., 1983. Coupling pests to crop growth simulators to predict yield reductions. Phytopathology 73, 1581-1587.

Brown, S., Csinos, A., Díaz-Pérez, J.C., Gitaitis, R., LaHue, S.S., Lewis, J., et al. 2005a. Tospoviruses in solanaceae and other crops in the coastal plain of Georgia. College of Agriculture and Environmental Sciences, University of Georgia Research Report (ISSN 0072-128X) 704:19.

Brown, S.L., Culbreath, A.K., Todd, J.W., Gorbet, D.W., Baldwin, J.A., Beasley, J.P., 2005b. Development of a method of risk assessment to facilitate integrated management of spotted wilt of peanut. Plant Dis. 89, 348-356.

Brown, S.L., Todd, J.W., Culbreath, A.K., Baldwin, J., Beasley, J., Kemerait, B., et al., 2008. Minimizing disease of peanut in the southeastern United States. In: 2008 Peanut Update. University of Georgia, Cooperative Extension Service, College of Agriculture and Environmental Sciences. CSS-08-0114, pp. 36-52.

Cantonwine, E.G., Culbreath, A.K., Stevenson, K.L., Kemerait Jr., R.C., Brenneman, T.B., Smith, N.B., et al., 2006. Integrated disease management of leaf spot and spotted wilt of peanut. Plant Dis. 90, 493-500.

Chaisuekul, C., Riley, D.G., 2005. Host plant, temperature, and photoperiod effects on ovipositional preference of Frankliniella occidentalis and Frankliniella fusca (Thysanoptera: Thripidae). J. Econ. Entomol. 98, 2107-2113.

Cu, R.M., Phipps, P.M., 1993. Development of a pathogen growth response model for the Virginia peanut leaf spot advisory program. Phytopathology 83, 195-201.

Culbreath, A.K., Stevenson, K.L., Brenneman, T.B., 2002. Management of late leaf spot of peanut with benomyl and chlorothalonil: A study in preserving fungicide utility. Plant Dis. 86, 349-355.

Culbreath, A.K., Todd, J.W., Brown, S.L., 2003. Epidemiology and management of tomato spotted wilt in peanut. Annu. Rev. Phytopathol. 41, 54-75.

Dacom, 2003. Crop management with plant-plus. Emmen, Dacom Plant Service.

Damicone, J.P., Jackson, K.E., Sholar, J.R., Gregory, M.S., 1994. Evaluation of a weather-based spray advisory for management of early leaf spot of peanut in Oklahoma. Peanut Sci. 21, 115-121.

Das, H.P., Doblas-Reyes, F.J., Garcia, A., Hansen, J.W., Mariani, L., Nain, A., et al., 2007. Weather and climate forecasts for agriculture. Ch. 4 In: Stigter, K. et al. (Ed.), Guide to Agricultural Meteorological Practices (GAMP), Draft third ed. WMO-No.134. World Meteorological Organization, Rome. <http://www.wmo.ch/pages/ prog/wcp/agm/gamp/gamp_en.html/> (accessed November 2012).

Dawidziuk, A., Kaczmarek, J., Jedryczka, M., 2012. The effect of winter weather conditions on the ability of pseudothecia of Leptosphaeria maculans and L. biglobosa to release ascospores. Eur. J. Plant Pathol. 134 (2), 329-343.

De Wolf, E.D., Isard, S.A., 2007. Disease cycle approach to plant disease prediction. Annu. Rev. Phytopathol. 45, 203-220.

Edelson, J.V., Magaro, J.J., 1988. Development of onion thrips, Thrips tabaci Lindeman, as a function of temperature. Southwestern Entomol. 13, 171-176.

Grichar, W.J., Jaks, A.J., Besler, B.A., 2005. Response of peanuts (Arachis hypogaea) to weather-based fungicide advisory sprays. Crop Prot. 24, 349-354.

Groves, R.L., Walgenbach, J.F., Moyer, J.W., Kennedy, G.G., 2002. The role of weed hosts and tobacco thrips, Frankliniella fusca, in the epidemiology of Tomato spotted wilt virus. Plant Dis. 86, 573-582.

Groves, R.L., Walgenbach, J.F., Moyer, J.W., Kennedy, G.G., 2003. Seasonal dispersal patterns of Frankliniella fusca (Thysanoptera: Thripidae) and tomato spotted wilt virus occurrence in central and eastern North Carolina. J. Econ. Entomol. 96, 1-11.

Harding, J.A., 1961. Effect of migration, temperature, and precipitation on thrips infestations in south Texas. J. Econ. Entomol. 54, 77-79.

Hartman, G.L., Noel, G.R., Gray, L.E., 1995. Occurrence of soybean sudden death syndrome in east-central Illinois and associated yield losses. Plant Dis. 79, 314-318.

Hoogenboom, G., 2000. The Georgia automated environmental monitoring network. Reprints of the 24th Conference on Agricultural and Forest Meteorology. American Meteorological Society, Boston, pp. 24-25.

Hoogenboom, G., 2001. Weather monitoring for management of water resources. In: Hatcher, K.J. (Ed.), Proceedings of the 2001 Georgia Water Resources Conference. Institute of Ecology, The University of Georgia, Athens, GA, pp. 778-781.

Hoogenboom, G., Coker, D.D., Edenfield, J.M., Evans, D.M., Fang, C., 2003. The Georgia automated environmental monitoring network: 10 years of weather information for water resources management. In: Hatcher, K.J. (Ed.), Proceedings of the 2003 Georgia Water Resources Conference, The University of Georgia, Athens, GA, pp. 896-900.

Jacobi, J.C., Backman, P.A., Davis, D.P., Brannen, P.M., 1995a. AU-Pnuts advisory II: modification of the rulebased leaf spot advisory system for a partially resistant peanut cultivar. Plant Dis. Rep. 79, 672-676. 
Jacobi, J.C., Backman, P.A., Davis, D.P., Brannen, P.M., 1995b. AU-Pnuts advisory I: development of a rulebased system for scheduling peanut leaf spot fungicide applications. Plant Dis. Rep. 79, 666-671.

Jensen, R.E., Boyle, L.W., 1965. The effect of temperature, relative humidity and precipitation on peanut leaf spot. Plant Dis. Rep. 49, 810-814.

Jensen, R.E., Boyle, L.W., 1966. A technique for forecasting leafspot on peanut. Plant Dis. Rep. 50, 810-814.

Jewell, E.L., 1987. Correlation of early leaf spot disease in peanut with a weather-dependent infection index. M.S. thesis. Virginia Polytechnic Institute and State University, Blacksburg, VA, p. 55.

Jones, J.W., Hoogenboom, G., Porter, C.H., Boote, K.J., Batchelor, W.D., Hunt, L.A., et al., 2003. The DSSAT cropping system model. Eur. J. Agron. 18, 235-265.

Katayama, H., 1997. Effect of temperature on development and oviposition of western flower thrips Frankliniella occidentalis (Pergande). Jpn. J. Appl. Entomol. Zool. 41, 225-231.

Kemerait, R.C., 2006. Peanut. In: (2005) Georgia Plant Disease Loss Estimate, compiled by Alfredo Martinez. The University of Georgia, College of Agricultural and Environmental Sciences, Cooperative Extension Special Bulletin 41-08, 11.

Kirk, W.D.J., 1997. Distribution, abundance, and population dynamics. In: Lewis, T. (Ed.), Thrips as Crop Pests CAB Wallingford, Oxon, UK, pp. 217-258.

Kirk, W.D.J., 2004. The link between cereal thrips and thunderstorms. Acta Phytopathol. Entomol. Hung. 39, 13-16.

Lewis, T., 1964. The weather and mass flights of Thysanoptera. Ann. Appl. Biol. 53, 165-170.

Lewis, T., 1965. The species, aerial density and sexual maturity of Thysanoptera caught in mass flights. Ann. Appl. Biol. 55, 219-225.

Lewis, T., 1973. Thrips: Their Biology, Ecology and Economic Importance. Academic Press, London, 349 pp.

Lewis, T., 1997. Flight and dispersal. In: Lewis, T. (Ed.), Thrips as Crop Pests. CAB, Oxon, UK.

Linvill, D.E., Drye, C.E., 1995. Assessment of peanut leaf spot disease control guidelines using climatological data. Plant Dis. 79, 876-879.

Lowry, V.K., Smith Jr., J.W., Mitchell, F.L., 1992. Life fertility tables for Frankliniella fusca and F. occidentalis on peanut. Ann. Entomol. Soc. Am. 85, 744-754.

Magarey, R.D., Fowler, G.A., Borchert, D.M., Sutton, T.B., Colunga-Garcia, M., Simpson, J.A., 2007. NAPPFAST: An internet system for the weather-based mapping of plant pathogens. Plant Dis. 91, 336-345.

Matra, A.D., Magarey, R.D., Orlandini, S., 2005. Modelling leaf wetness duration and downy mildew simulation on a grapevine in Italy. Agric. For. Meteorol. 132, 84-95.

McDonald, J.R., Bale, J.S., Walters, K.F.A., 1998. Effect of temperature on development of the western flower thrips, Frankliniella occidentalis (Thysanoptera: Thripidae). Eur. J. Entomol. 95, 301-306.

McPherson, R.M., Pappu, H.R., Jones, D.C., 1999. Occurrence of five thrips species on flue-cured tobacco and impact on spotted wilt disease incidence in Georgia. Plant Dis. 83, 765-767.

Mitchell, F.L., Smith, J.W. Jr., 1991. Epidemiology of tomato spotted wilt virus relative to thrips populations. VirusThrips-Plant Interactions of Tomato Spotted Wilt Virus. Proceedings of a USDA Workshop. USDA-ARS Bulletin ARS-87:46-52.

Morsello, S.C., 2007. The Role of Temperature and Precipitation on Thrips Populations in Relation to the Epidemiology of Tomato Spotted Wilt Virus. Ph.D. Thesis. Department of Entomology, North Carolina State University, Raleigh, NC.

Morsello, S.C., Groves, R.L., Nault, B.A., Kennedy, G.G., 2008. Temperature and precipitation affect seasonal patterns of dispersing tobacco thrips, Frankliniella fusca, and onion thrips, Thrips tabaci (Thysanoptera: Thripidae) caught on sticky traps. Environ. Entomol. 37, 79-86.

Nokes, S.E., Young, J.H., 1991. Simulation of the temporal spread of leafspot and the effect on peanut growth. Trans. ASAE 34, 653-662.

Olatinwo, R., Becker, J.O., Borneman, J., 2006a. Suppression of Heterodera schachtii populations by Dactylella oviparasitica in four soils. J. Nematol. 38, 345-348.

Olatinwo, R., Borneman, J., Becker, J.O., 2006b. Induction of beet-cyst nematode suppressiveness by the fungi Dactylella oviparasitica and Fusarium oxysporum in field microplots. Phytopathology 96, 855-859.

Olatinwo, R., Yin, B., Becker, J.O., Borneman, J., 2006c. Suppression of the plant-parasitic nematode Heterodera schachtii by the fungus Dactylella oviparasitica. Phytopathology 96, 111-114.

Olatinwo, R.O., Paz, J.O., Brown, S.L., Kemerait, R.C., Culbreath, A.K., Beasley Jr, J.P., et al., 2008. A predictive model for spotted wilt epidemics in peanut based on local weather conditions and the Tomato spotted wilt virus risk index. Phytopathology 98, 1066-1074.

Olatinwo, R.O., Paz, J.O., Brown, S.L., Kemerait Jr., R.C., Culbreath, A.K., Hoogenboom, G., 2009. Impact of early spring weather factors on the risk of tomato spotted wilt in peanut. Plant Dis. 93, 783-788.

Olatinwo, R.O., Paz, J.O., Kemerait, R.C., Culbreath, A.K., Hoogenboom, G., 2010. El Ninõ-Southern Oscillation (ENSO): Impact on tomato spotted wilt intensity in peanut and the implication on yield. Crop Prot. 29, $448-453$.

Olatinwo, R.O., Prabha, T.V., Paz, J.O., Riley, D.G., Hoogenboom, G., 2011. The weather research and forecasting (WRF) model: application in prediction of TSWV-vectors populations. J. Appl. Entomol. 135 (1-2), 81-90. 
Olatinwo, R.O., Prabha, T.V., Paz, J.O., Hoogenboom, G., 2012. Predicting favorable conditions for early leaf spot of peanut using output from the weather research and forecasting (WRF) model. Int. J. Biometeorol. 56, 259-268.

Parvin, D.W., Smith, D.H., Crosby, F.L., 1974. Development and evaluation of a computerized forecasting method for Cercospora leaf spot of peanuts. Phytopathology 64, 385-388.

Pearsall, I.A., Myers, J.H., 2001. Spatial and temporal patters of dispersal of western flower thrips (Thysanoptera: Thripidae) in nectarine orchards in British Columbia. J. Econ. Entomol. 94, 831-843.

Pimentel, D., 1991. CRC Handbook of Pest Management in Agriculture, Vol. 1 second ed. CRC Press, Boca Raton, FL.

Prabha, T., Hoogenboom, G., 2008. Evaluation of the weather research and forecasting model for two frost events. Comput. Electron. Agric. 64, 234-247.

Prior, C., Streett, D.A., 1997. Strategies for the use of entomopathogens in the control of the desert locust and other acridoid pests. Mem. Entomol. Soc. Can. 171, 5-25.

Riley, D.G., Pappu, H.R., 2000. Evaluation of tactics for management of thrips-vectored Tomato spotted wilt virus in tomato. Plant Dis. 84, 846-852.

Riley, D.G., Pappu, H.R., 2004. Tactics for management of thrips (Thysanoptera: Thripsidae) and tomato spotted wilt virus in tomato. J. Econ. Entomol. 97, 1648-1658.

Roberts, P.A., Thomason, I.J., 1981. Sugarbeet Pest Management: Nematodes. University of California Division of Agriculture Sciences Publications, 3272. University of California, Oakland, CA.

Rosenzweig, C., Iglesias, A., Yang, X.B., Epstein, P.R., Chivian, E., 2000. Implications of Climate Change for U.S. Agriculture: Extreme Weather Events, Plant Diseases, and Pests. Cambridge, MA: Center for Health and the Global Environment, Harvard Medical School. Cambridge, MA, 56 pp.

Rosenzweig, C., Iglesias, A., Yang, X.B., Epstein, P.R., Chivian, E., 2001. Climate change and extreme weather events. Implications for food production, plant diseases, and pests. Glob. Chang. Hum. Health 2, 90-104.
Roy, K.W., Rupe, J.C., Hershman, D.E., Abney, T.S., 1997. Sudden death syndrome. Plant Dis. 81, 1100-1111.

Scherm, H., van Bruggen, A.H.C., 1993. Sensitivity of simulated dew duration to meteorological variations in different climatic regions of California. Agric. For. Meteorol. 66, 229-245.

Seeley, S.D., 2002. Reducing Chemical Inputs in Arid Climates through Sustainable Orchard Management. Department of Plants, Soils, and Biometeorology, Utah State University, Logan, UT.

Shew, B.B., Beute, M.K., Wynne, J.C., 1988. Effects of temperature and relative humidity on expression of resistance to Cercosporidium personatum in peanut. Phytopathology 78, 493-498.

Strand, J.F., 2000. Some agrometeorological aspects of pest and disease management for the 21st century. Agric. For. Meteor. 103, 73-82.

Todd, J.W., Culbreath, A.K., Chamberlin, J.R., Beshear, R.J., Mullinix, B.J., 1995. Colonization and population dynamics of thrips in peanuts in the southern United States. In: Parker, B.L., Skinner, M., Lewis, T. (Eds.), Thrips Biology and Management. Plenum, New York, pp. 453-460.

Tsuji, G.Y., Hoogenboom, G., Thornton, P.K., 1998. Understanding Options for Agricultural Production. Kluwer Academic Publishers, Dordrecht, The Netherlands.

Weiss, A., 1990. The role of climate-related information in pest management. Theor. Appl. Climatol. 41, 87-92.

Wharton, P.S., Kirk, W.W., Baker, K.M., Duynslager, L., 2008. A web-based interactive system for risk management of potato late blight in Michigan. Comput. Electron. Agric. 61, 136-148.

Woodward, J.E., Brenneman, T.B., Kemerait Jr., R.C., Culbreath, A.K., Smith, N.B., 2010. Management of peanut diseases with reduced input fungicide programs in fields with varying levels of disease risk. Crop Prot. 29, 222-229.

Wu, L., Damicone, J.P., Duthie, J.A., Melouk, H.A., 1999. Effects of temperature and wetness duration on infection of peanut cultivars by Cercospora arachidicola. Phytopathology 89, 653-659.

Yang, X.B., Scherm, H., 1997. El Niño and infectious disease. Science $275,739$. 